\title{
Disintegration Rate of Carbon-14
}

\author{
R. S. Caswell, J. M. Brabant, ${ }^{1}$ and A. Schwebel
}

\begin{abstract}
The energy emission rates of $\mathrm{C}^{14}$ samples have been measured with an extrapolation ionization chamber. From the energy emission rates, the disintegration rates are determined through knowledge of the average beta-ray energy emitted per disintegration. From earlier data on the isotopic abundance, a value for the half-life of $\mathrm{C}^{14}$ of $5,900 \pm 250$ years is obtained.
\end{abstract}

In view of the large discrepancies existing between various determinations of disintegration rate (and consequently of the half-life) of carbon-14 [1], ${ }^{2}$ a measurement by an independent method has seemed desirable. In the present work an extrapolation chamber measurement of the energy emission of a $\mathrm{C}^{14}$ sample is combined with the average energy per disintegration from beta-ray spectrometer measurements to yield the disintegration rate. The half-life is then determined by using previously reported measurements of isotopic abundance [1]. The disintegration rate is found by the relation $\dot{E}_{m}=\dot{n} \bar{E}$, where $\dot{E}_{m}$ is the energy produced per second per gram of material, $n$ is the number of disintegrations per second per gram, and $\bar{E}$ is the average energy per disintegration. Using the number of $\mathrm{C}^{14}$ atoms per gram, $n$, (from mass-spectrometer measurement) the half-life is determined by the relation $\dot{n}=-0.693 n$ / $T_{1 / 2}$

The type of extrapolation chamber used here has previously been used in combination with 4-pi beta counting to determine the average energy of beta-ray spectra $[2,3]$. The excellent agreement between average energies determined in this way and average energies calculated from spectrometer data or from beta-decay theory (using experimental values for $E_{\max }$ ) demonstrates that the extrapolation chamber does measure $\dot{E}_{m}$ to good accuracy. Nuclides previously studied range in energy from $\mathrm{Ca}^{45}(\bar{E}=$ $0.075 \mathrm{Mev})$ to $\mathrm{Y}^{90}\left(\overline{\boldsymbol{E}^{\prime}}=0.895 \mathrm{Mev}\right)$.

The theory of the extrapolation chamber has been discussed elsewhere $[2,4]$. The energy production rate for an air-cavity water-electrode chamber is given by the Bragg-Gray cavity theorem [5]: $\dot{E}_{m}=J_{m} W_{a i \tau} \rho_{m}$, where $J_{m}$ is the number of ion pairs formed per gram of air per second, $\rho_{m}$ is the mass stopping power of the water relative to air, and $W_{a i r}$ the average energy required to produce an ion pair in air. In the present experiment, one electrode was aluminum and the other was a dilute, thoroughly mixed water solution of $\mathrm{C}^{14}$ (as $\mathrm{Na}_{2} \mathrm{CO}_{3}$ ). In this case $E_{m}=2 J_{m} W_{\text {air }} \rho_{m} / B$, where $B$ is called the "backscattering correction factor." $B$ has been evaluated experimentally by comparison with a water backscattering electrode (solidified with agar), and by extrapolation chamber studies of the variation of backscattering with atomic number [2]. $B$ is found to

1 Now at University of California, Berkeley, Calif.

${ }^{2}$ Figures in brackets indicate the literature references at the end of this paper. be remarkably independent of beta energy (varying by less than $2 \%$ from $\mathrm{P}^{32}$ to $\mathrm{S}^{35}$ ) and is taken as 1.125 for $\mathrm{C}^{14}$. The relative stopping power of water to air, $\rho_{m}$, is taken as 1.13 , which is the ratio of the number of electrons per gram of the two media $(1,11)$, corrected for the difference in stopping power caused by the effective ionization potentials of water and air. Failla and Rossi [6] have reported a value of $W_{a i r}=$ $32.5 \mathrm{ev}$ per ion pair for $\mathrm{S}^{35}$, which should be very close to the value for $\mathrm{C}^{14}$ because both nuclides have the same spectrum shape and nearly the same beta energy. This value agrees with that calculated by Wang [7] from the formula of Gerbes by averaging over the energy of the electrons from the initial energy until brought to rest. For this report, we take $W_{a i \tau}=32.5$ ev per ion pair. A recent review by Binks [8] of a large number of measurements of $W_{a i r}$ indicates $33 \mathrm{ev}$ per ion pair may be preferable. If so, the results of this experiment should be changed accordingly.

The average beta energy of $\mathrm{C}^{14}$ was numerically calculated to be $49.7 \mathrm{kev}$, using $155 \mathrm{kev}$ for the maximum energy [9] and considering the beta spectrum as "allowed" [10].

The amount of $\mathrm{C}^{14}$ in the water solution, $n$, was determined by comparison with standard ampoules prepared by Manov [1,11] and on which mass spectrometer measurements have been made in four laboratories. The standard sample is taken as having $3.132 \times 10^{14}$ atoms of $\mathrm{C}^{14}$ per milliliter of solution. The value of $n$ for the experimental sample is determined by evolving $\mathrm{CO}_{2}$ from both standard and experimental solutions and observing the relative ionization currents in a $\mathrm{CO}_{2}$-filled ionization chamber.

Three runs were made, giving values of $\dot{n}$ of 12.55 $\mu \mathrm{c} / \mathrm{ml}, 4.53 \mu \mathrm{c} / \mathrm{ml}$, and $1.49 \mu \mathrm{c} / \mathrm{ml}$, respectively. The corresponding values of $n$ were $1.25 \times 10^{17}$ atoms $/ \mathrm{ml}$, $4.53 \times 10^{16}$ atoms $/ \mathrm{ml}$, and $1.47 \times 10^{16}$ atoms $/ \mathrm{ml}$, respectively. These runs yield values for the half-life of $\mathrm{C}^{14}$ of 5,900 years, 5,940 years, and 5,840 years, respectively. The third run is of somewhat lower accuracy than the first two because of the low activity of the sample.

In terms of the disintegration rate values assigned to the standard ampoules by Manov and Curtiss [11] based on $\mathrm{CO}_{2}-\mathrm{CS}_{2}$ gas counting, the disintegration rates, $\dot{n}$, for the present samples should have been $13.8 \mu \mathrm{c} / \mathrm{ml}, 5.01 \mu \mathrm{c} / \mathrm{ml}$, and $1.62 \mu \mathrm{c} / \mathrm{ml}$, respectively. These values are systematically about 9 percent higher than the values obtained in the present work. This comparison (which is independent of 
isotopic abundance measurements) shows a discrepancy of 9 percent.

This discrepancy is of the same order as the uncertainties in the gas-counting method itself as shown by disintegration-rate intercomparisons [1] and indirectly by the half-life determinations (table 1). The recent work of Crane [12] suggests the possibility of multiple counts in $\mathrm{CO}_{2}-\mathrm{CS}_{2}$ counters due to production of pulses by both electrons and negative ions.

Table 1 shows a comparison of recent half-life values obtained by gas counting, calorimetric measurement, and the present method. " $n$ " was determined by mass spectrometer measurement in all cases except for the calorimeter. In the calorimetric measurement we have used our value (49.7 kev) for the average energy of the beta spectrum. Probable errors in the present measurements are taken as: $W_{a i r}, \pm 3$ percent; $\dot{J}_{m}, \pm 1$ percent, $B$, \pm 1.5 percent; $\rho_{m}, \pm 1$ percent; $n, \pm 1.6$ percent; $\bar{E}, \pm 1$ percent, giving an over-all probable error in the half-life of about 250 years.

TABLE 1. [13]

\begin{tabular}{|c|c|c|}
\hline Authors & $\begin{array}{c}\text { Method of disintegration rate } \\
\text { determination }\end{array}$ & $T_{1 / 2}$ \\
\hline $\begin{array}{l}\text { Hawkings, Hunter, Mann, } \\
\text { and Stevens. } \\
\text { Engelkemeir and Libby } \\
\text { Jones } \\
\text { Manov and Curtiss [11] } \\
\text { Miller, et al } \\
\text { Jenks and Sweeton } \\
\text { Present work }\end{array}$ & $\begin{array}{l}\mathrm{CO}_{2}+\mathrm{CS}_{2} \text { (GM counter) } \\
\mathrm{CO}_{2}+\text { argon-alcohol (GM counter) } \\
\mathrm{CO}_{2}+\text { argon-alcohol (GM counter) } \\
\mathrm{CO}_{2}+\mathrm{CS}_{2} \text { (GM counter) } \\
\mathrm{CO}_{2}+\mathrm{CS}_{2}(\mathrm{GM} \text { counter) } \\
\mathrm{CO}_{2}+\text { methane (prop. counter) } \\
\mathrm{Calorimeter} \text { (and gas density } \\
\text { measurement for } n \text { ). } \\
\text { Extrapolation chamber......... }\end{array}$ & \begin{tabular}{l}
\multicolumn{1}{c}{ Years } \\
$6,360 \pm 200$ \\
$5,580 \pm 45$ \\
$5,589 \pm 75$ \\
$5,370 \pm 200$ \\
6,400 \\
5,600 \\
6,090 \\
$5,900 \pm 250$
\end{tabular} \\
\hline
\end{tabular}

The present value is in best agreement with the calorimeter measurements, which also depend upon energy emission rather than a direct disintegrationrate determination. The present value is not in good agreement with either group of gas-counting measurements (about 5,500 years and 6,400 years). In view of the excellent beta-ray spectrometer data on $\mathrm{C}^{14}$, it appears very unlikely that any uncertainty in $\bar{E}$ can account for the difference. No large error should be present in $\left(W_{a i r} \rho_{m} / B\right)$ because this quantity has been independently checked in the previous average energy measurements. For example, $\mathrm{Ca}^{45}$ has an average energy about 1.5 times that of $\mathrm{C}^{14}$ and also has an "allowed" spectrum. With the same value of $\left(W_{a i r} \rho_{m} / B\right)$ used here, the disintegration rate of a $\mathbf{C a}^{45}$ source determined by extrapolation chamber coincided with a value determined by $4-\pi$ counting within 1 percent.

In conclusion, a reinvestigation of disintegration rate measurements by several independent methods appears desirable. Considerable emphasis should be placed on calorimeter measurements of disintegration rate because they involve a minimum of uncertainty. These measurements should be done on a sample of high specific activity in conjunction with isotopic abundance measurements. Further studies of this nature are under way in the Radioactivity Section at the National Bureau of Standards.

We are indebted to the University of Kentucky and to T. I. Davenport of the National Bureau of Standards for the loan of the equipment used.

\section{References}

[1] G. G. Manov, National Research Council Nuclear Science Series Preliminary Report No. 13 (1953).

[2] R. S. Caswell, Phys. Rev. 86, 82 (1952).

[3] J. M. Brabant, L. W. Cochran, and R. S. Caswell, Phys. Rev. 91, 210A (1953).

[4] G. Failla, H. H. Rossi, R. K. Clark, and N. Baily, U. S. Atomic Energy Commission Document 2142.

[5] L. H. Gray, Proc. Roy. Soc. (London) 156A, 578 (1936).

[6] G. Failla and H. H. Rossi, U. S. Atomic Energy Commission Report NYO-4008 (1952).

[7] T. J. Wang, Nucleonics 7, No. 2, 55 (1950).

[8] W. Binks, Report for British Committee on Radiological Units BRU/40 (to be published in Acta Radiologica).

[9] K. Way et al., NBS Circular 499.

[10] C. S. Wu and A. Schwarzschild, Phys. Rev. 91, 483A (1953).

[11] G. G. Manov, and L. F. Curtiss, J. Research NBS 46, 328 (1951) RP2203.

[12] H. R. Crane, Bul. Am. Phys. Soc. 29, 39 (1954).

[13] R. C. Hawkings, R. F. Hunter, W. B. Mann, and W. H. Stevens, Can. J. Research B\%7, 545 (1949); A. G. Engelkemeir and W. F. Libby, Rev. Sci. Instr. 21, 550 (1950); W. M. Jones, Phys. Rev. 76, 885 (1949); W. W. Miller, R. Ballentine, W. Bernstein, L. Friedman, A. O. Nier, and R. D. Evans, Phys. Rev. $7 \boldsymbol{y}, 714$ (1950); G. H. Jenks and F. H. Sweeton, Phys. Rev. 86, 803 (1952).

Washington, March 1, 1954. 